\title{
Analysis on Teaching Practice Mode of Social Sports Specialty in Hubei University of Science and Technology
}

\author{
Shuangjun Li \\ The Department Of Physical Education of Hubei University of Science and Technology, Xianning, Hubei, \\ China
}

Keywords: professional practice; teaching practice; thinking

\begin{abstract}
By means of data and expert interviews, this paper focuses on the study of practice teaching mode of social sports specialty in Hubei University of Science and Technology, and analyzes its training objectives, professional curriculum, practice content and base, practice form and time, and according to the feedback from practice base, finds out the shortcomings and summarizes the advantages. At last, it gives some development ideas. For example, to strengthen the construction of teachers, the teaching practice process should be further improved, and there should be a more standardized and powerful practice base which can meet the teaching objectives of the college. In this way, colleges and universities can cultivate more excellent students and improve their comprehensive ability to adapt to the society. Under the pressing employment situation, students can develop in an all-round way, integrate into the society better and faster, and make them have better development and employment prospects.
\end{abstract}

\section{Introduction}

\subsection{The objectives of personnel training}

The training goal is formulated by the Institute in accordance with the educational purpose, the characteristics of the development of the school and the needs and requirements of the society, which embodies the educational purpose. The major of social sports in Hubei University of Science and Technology is to cultivate the innovation and applied talents who have all-round development of morality, intelligence, physique and beauty, and have better scientific and cultural accomplishment and high sense of social responsibility, master the basic theory and method of social sports, possess the ability of body-building guidance, planning and organizing mass sports activities, and management of sports industry, also have the ability of organization and management, fitness consultation, technical guidance and other aspects .From the training goal, we can see that the school is training "applied talents", which is consistent with the social sports to complete the task, is the inevitable requirement of social sports. In order to meet the needs of the society for talents, the training process should keep in touch with the society, keep in touch with the society and keep in touch with the social development.

According to a general survey, the employment rate of social sports major in the department of physical e ducation is 48.2\%, 19.1\% and 17.4\% in 2012, 2013 and 2014 respectively. Flexible employment accounts for the vast majority of graduates. In addition to entering school, most of them go to fitness clubs, but also a small number of primary and secondary school PE teachers, only a small number of enterprises to take up jobs not related to sports. The survey results show that the graduate employment is in line with the school's personnel training objectives.

\subsection{Professional curriculum}

The basic courses of social sports major in Hubei University of Science and Technology are divided into compulsory courses for social sports major and elective courses for social sports major. Such as some major courses: Introduction to Social Sports, Sports Marketing, Sports Sociology, Exercise Psychology, Traditional Health Conservation, Sports Biological Science Foundation, Sports and Physical Education. Health Care Science, Fitness Sports Theory and Method, Health 
Physical Fitness Evaluation and Exercise Prescription, Main Items, etc. There are also many main events, such as aerobics, fitness, taekwondo, and so on, which match the needs of society.

\subsection{Form and time of teaching practice}

The mode of teaching practice is to apply the theory and practice that we usually learn to professional practice. Teaching practice forms are divided into in-school practice (centralized practice) and off-campus practice (centralized practice - school-enterprise cooperation and decentralized practice).

\subsubsection{Internship}

According to the relevant requirements of the training plan and the practice work plan of Hubei Institute of Science and Technology, combined with the actual work of the Institute of Physical Education and the characteristics of the major of social physical education, students are instructed by professional teachers in the past three and a half months, and practice in different classes in different stages. Line guidance, running the simulated fitness club on campus, preparing students for off campus practice in senior four.

The objectives of school practice are: (1)To apply the professional knowledge and theories learned to practical work and bring them into full play. (2) Understand the development trend, operation mode and operation characteristics of health industry in simulated internship units (departments), and analyze the marketing environment of simulated internship units, including macro and micro environment. (3) Understanding the establishment of the organizational structure, the functions and management system of the enterprise management, opening up the market, formulating the management plan and decision-making, the characteristics of the sports products, the methods of cost accounting, the formulation of the price and the integrated management of the products before, during and after sales. . (4) Understand the general working principle of fitness equipment and fitness equipment in simulated internship units, and learn how to operate and maintain fitness equipment. (5) Learn to guide different classes, different groups of people, different ages, different sexes of people's fitness and recreational activities, and according to its characteristics to develop a more scientific and practical exercise prescription. (6) Using the basic methods and means of physiotherapy, acupuncture and massage, according to the actual situation of the fitness object, using different methods of relaxation and massage, using the methods and principles of rescue and treatment of common injuries and emergencies, according to the actual situation of the fitness object to implement on-the-spot first aid. (7) Analyzing and studying the improvement of physiological indexes in body-building exercise, and understanding the difference of physiological function between people who often engage in body-building exercise and those who seldom engage in body-building exercise. (8) Using the basic knowledge of nutrition to analyze and study the general nutritional status of modern people can help consumers to formulate a more scientific and practical diet and dietary therapy. (9) Using the basic principles of mass fitness and bodybuilding, according to the fitness needs of exercisers, choose appropriate fitness methods and projects, and conduct scientific fitness guidance. (10)Understand the planning, organization and arrangement of major sports activities.

\subsubsection{Off campus internship (after internship practice)}

The off-campus practice is a link in the four-year training process. Through this link, students have a preliminary understanding and practical experience of the working environment, working conditions and service groups of the corresponding units. In the seventh semester, the students of Physical Education Institute of Hubei University of Science and Technology have a four-month intensive practice. The practice is carried out by the school in conjunction with the practice units, starting from the students of grade 2014, in the mode of school-enterprise cooperation. According to the number of interns and the special needs of the practice units, the students are organized into a number of practice teams, equipped with leading teachers and in accordance with the unification. The time required to practice in the internship unit. During the internship period, the leaders and teachers of the college will go to the practice base for inspection. The advantages of this practice 
mode are: (1) The practice unit (enterprise club) has been selected after investigation. The Club generally has better practice conditions and guidance conditions for the interns. The training program in the practice stage can be implemented and its effect can be achieved. Guarantee. (2) Organizational management is normative and unified. (3) We can get the feedback information of the student's practice situation in time, the college and the enterprise jointly guide and train the student to practice.

Through centralized practice in the club, students have mastered some skills and skills by applying what they have learned. Students in the eighth semester for 14 weeks of scattered practice, students have some work experience, under the pressure of difficult employment, according to their actual situation, can choose to be conducive to their employment and suitable work units, to achieve effective docking, give full play to the ability of students.

\section{The insufficiency of teaching practice mode}

\subsection{Need to perfect the school practice base}

There is no school internship base. There are venues, teachers, venues and equipment to build fitness clubs in schools. At present, there is a lack of teachers and facilities. Teachers such as the direction of fitness and fitness, students only master this knowledge and skills can be competent for fitness clubs.

\subsection{The practice evaluation system needs to be further improved}

The evaluation system of professional practice in P.E. Institute is composed of the evaluation of instructors in practice and the evaluation of instructors in practice clubs outside the school. Because students are not exactly the same in practice and content, and because there is no good supervision mechanism for the eighth semester of practice, the three general evaluations of students' practice are made. The assessment of performance is too general. In this way, the evaluation of students' practical ability will lead to students can not understand their performance in each practice link from the score, so the college should divide the practice link into several links to check and guide the evaluation, and establish a sound evaluation and incentive system. In this way, students have an accurate judgment and positioning of their practical ability, have a certain degree of guidance for their own development direction, and strive to improve it.

\subsection{Further guide teaching practice objects.}

As for the object of teaching practice, due to the factors such as the motivation of most students, their values, the employment environment, the way of choosing a job, and the changes of real interests, they do not have good professional ideas, which are manifested in their inadequate learning attitude, lack of professional knowledge and weak professional concepts, and a large number of students have changed their professions. Inclined or ready to change. Teachers should give correct guidance and guidance to students in this respect.

\section{Thinking of developing a good teaching practice mode}

\subsection{Strong support from the leading departments.}

The practice of this major is carried out under the leadership of the school's educational administration department, and the professional practice is included in the teaching plan. With the help of the Department of Education and the strong support of the leadership of the Institute of Physical Education, the College has included professional internships in its annual work plan. The strong support from the leading departments is a powerful guarantee for achieving good results in the internship.

\subsection{Good teachers.}

Teachers are professionals who transmit and disseminate human civilization, knowledge and 
skills. Teachers should not only love their posts and work hard, have a high sense of responsibility and professional ethics, but also have a strong professional knowledge, sports ability and teaching skills. Therefore, we should strengthen the training of social sports teaching practice teachers, in the training of teachers should take into account the cross-cutting and applied characteristics of social sports.

\subsection{A perfect workflow.}

The process of internship in this major is (1) The Department of Social Physical Education formulates the internship work plan, and communicates with the physical education institute, the educational administration department and the off-campus internship units. (2) Special meetings were held among the leaders of the educational administration department, the sports institute, the social sports department and the practice units to study and formulate concrete implementation plans. (3) The school-enterprise cooperative unit receives interns and assigns them to the suitable practice base according to the different conditions between the interns and the interns. (4) Each practice base begins to conduct all-round guidance according to the training objectives of the practice stage, namely, the contents and requirements of the practice work plan.

\subsection{A management plan suitable for students' professional practice.}

Under the leadership of the internship leading group, the Department Director formulates a professional internship work plan, assigns the internship leading teacher to lead the students to the internship point to communicate with the internship unit, properly handles various unexpected incidents during the internship, and completes the internship appraisal, the achievement appraisal and the summary commendation work.

\subsection{Recommendations on specific practices in internship}

According to the summary of the school and students after the practice, we can arrange three semesters for professional practice, the first semester can be shorter, the school can arrange practice, the second semester and the third semester for a little longer practice. The purpose of the arrangement of the three semesters' professional practice is to make the students have a preliminary perception and experience of the professional practice, make ideological and professional preparations, and make the students know the objectives, content and process of the professional practice. According to some of the problems in their practice to reflect and re-study, to really complete the work of practice to lay the groundwork, so that their practice outside the school to do a better job, the time arrangement so that students through the practice of recognition and practice again and again in the process of practice. So that students can construct their own knowledge and skills and integrate them, so that some problems encountered in the practice can effectively use the knowledge and skills learned to solve problems, and constantly improve their practical ability in work. There must be at least a certain time interval between the three semesters of internship arrangements to ensure that students have time to complete the task of knowledge and skills reconstruction, so that each internship has some progress, and to find their own problems in the practice (such as interpersonal communication, knowledge structure and other shortcomings) to make up for It will lay a more solid foundation for the next internship..

\section{Acknowledgement}

Foundation project: Teaching and research subject atschool level in 2015 (2015-XC-016).

\section{References}

[1] Zhao Zhiying. Practice ability and training of sports majors in Higher Physical Education Institutes [D]. Beijing Sport University, 2011, 06

[2] Bai Li Fang. Research on teaching practice of social sports specialty [D]. Hunan Normal University, 2008, 05 
[3] Wang Fang. The Present Situation of Teaching Practice and Development Strategies of Social Physical Education Major in Colleges and Universities in China [D].Central China Normal University, 2008,04

[4] Cai Wenqian. Research on the Current Situation of Practical Teaching of Social Sports Instruction and Management in Hunan Province [D].Hunan University of Science and Technology, 2017, 05 